\title{
The performance of benzenesulfonic acid catalyst on the alkylation of thiophenic sulfur
}

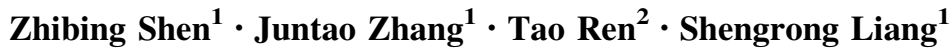

Received: 29 March 2015 / Accepted: 4 June 2015/Published online: 20 June 2015

(c) The Author(s) 2015. This article is published with open access at Springerlink.com

\begin{abstract}
Catalytic performance of benzenesulfonic acid was investigated for alkylation of thiophenic sulfur compounds with diene. The alkylates were confirmed by gas chromatography-mass spectrometry technique. The reaction conditions were optimized as follows: temperature is $85{ }^{\circ} \mathrm{C}$, catalyst/feed weight ratio is $10 \%$ and time is $80 \mathrm{~min}$. Under the conditions, the conversion of thiophene was nearly $73 \%$. The catalyst exhibited some recycle-use performance. The catalytic activity could be maintained by addition of the fresh catalyst periodically and quantitatively.
\end{abstract}

Keywords Desulfurization · Thiophene - Alkylation · Gasoline $\cdot$ Benzenesulfonic acid

\section{Introduction}

Deep desulfurization of gasoline has been an important research topic in recent years, as many countries are gradually strengthening the engine emission control regulations to alleviate environmental pollution. Especially for China, the new standards corresponding to Euro IV and V standards (the permitted maximum sulfur amount less than 50 and $10 \mathrm{ppm}$, respectively) have been carried out. Currently, most of the gasoline desulfurization is through the

Zhibing Shen

shen_zhibing@163.com; shenoil@sohu.com

1 School of Chemistry and Chemical Engineering, Xi'an Shiyou University, No. 18 Dianzi Er Road, Xi'an 710065, Shaanxi, China

2 The Northwest Research Institute of Chemical Industry, Xi'an 710054, Shaanxi, China hydrodesulfurization (HDS) process [1]. The typical techniques have the Prime $\mathrm{G}^{+}$[2], the CD Hydro/CD HDS [3], the OCTGAIN [4], and so on, which could produce Euro IV and Euro V standards. However, the octane number loss of gasoline is an inevitable problem for the hydrodesulfurization process.

Besides HDS, some non-HDS methods have also been introduced into gasoline desulfurization, including adsorptive desulfurization, oxide desulfurization and biological desulfurization. Especially for adsorptive desulfurization, the S-zorb process invented by Conoco Philips, claimed to preserve octane number well, while removing sulfur species effectively [5]. This technology could produce clean gasoline satisfactorily for Euro IV and V standards.

In recent years, alkylation of thiophenic sulfur, invented by BP [6], also has attracted some attention. This process includes two steps: First, under the action of some acidic catalysts, the thiophenic sulfur compounds were alkylated with diene or olefins in the gasoline. Second, the alkylated heavy thiophenes are separated from gasoline by distillation. This technology could accept Euro IV and V gasoline standards and avoid the octane number loss in the desulfurization process [7]. Ke et al. [8] showed that thiophenic sulfur compounds react preferentially with diene rather than mono-olefins in the gasoline over a weak acidic catalyst under mild reaction condition. Meanwhile, the weak acidity reduced some side reactions during the alkylation process, such as polymerization of olefins and alkylation between olefins and aromatics.

Several works investigated the alkylation of thiophenic sulfur catalysts. Many acidic catalysts are proposed, with either Brpnsted or Lewis acidity, including various zeolites ( $\beta$-zeolite, MCM-22, MCM-41, USY,..$)$, phosphoric acid on kieselguhr, $\mathrm{H}_{3} \mathrm{PW}_{12} \mathrm{O}_{40} / \mathrm{Fe}_{2} \mathrm{O}_{3}$, etc. [7, 9-12]. However, 
the acid catalyst causes easily the other competitive reactions under the alkylation conditions, such as the aromatics alkylation, polymerization of olefins or diene, over-alkylation of thiophene and so on. These can decrease catalytic activity and life of catalysts, especially for zeolite catalysts. In recent years, ionic liquids (ILs), as a kind of homogeneous catalysts, have been applied to the alkylation of thiophene with olefins (or diene) and have good catalytic performance [13, 14]. The acidity of ILs can be designed and adjusted through molecular design. The proper acidity can be chosen to make the catalyst have good catalytic performance in the alkylation process.

In this paper, benzenesulfonic acid as a catalyst for alkylation of thiophenic sulfur with diene was researched. Its catalytic reaction process is similar to ILs and belongs to homogeneous process, but the cost of benzenesulfonic acid is much less than that of ILs. Benzenesulfonic acid forms white deliquescent sheet crystals or a white waxy solid. Its melting point is $44{ }^{\circ} \mathrm{C}$ and boiling point is $137{ }^{\circ} \mathrm{C}$. Its acidity is nearly to that of sulfuric acid. As the reaction conditions of alkylation reaction are mild, benzenesulfonic acid melts to catalyze the alkylation of thiophenic sulfur in the gasoline during the reaction process. In addition, after reaction and cooling the reaction system, benzenesulfonic acid grows solid. Therefore, the catalyst is easy to be separated from product and can be recycled. To investigate the catalytic performance of benzenesulfonic acid for alkylation of thiophenic sulfur with diene, the alkylates between thiophene and 2,5-dimethyl-1,5-hexadiene were identified by GC-MS. Effect of olefins on alkylation process, the optimum reaction conditions and the recycle-use performance of catalyst were also carried out.

\section{Experimental section}

\section{Chemicals}

Thiophene, 3-methyl-thiophene, 2-methyl-thiophene, 2, 5-dimethyl-thiophene, 2-methyl-5-ethyl-thiophene and benzenesulfonic acid were purchased from ACROS ORGANICS, chemical pure grade, and 2,5-dimethyl-1,5hexadiene produced by Tokyo Chemical Industry Co., Ltd. And octane and 1-hexene were purchased from Beijing Chemical Reagents Factory.

\section{Reaction system}

The reactor used for the catalytic tests is a $200 \mathrm{~mL}$ stirred slurry autoclave produced by Dalian Tong-Chan Autoclave Factory (Liaoning Province, China). The feed is a series of blended model oil, which is composed of $99.5 \mathrm{wt} \%$ octane, $0.5 \mathrm{wt} \%$ 2,5-dimethyl-1,5-hexadiene and $200 \mu \mathrm{g} / \mathrm{g}$ thiophenic sulfur compound. Catalytic runs were performed in the above-described reactor under the different reaction conditions.

\section{Analysis}

The sulphur compounds of products were identified by a gas chromatograph/mass spectrometer (GC/MS) (Shimadzu GC17A/QP-500) and analyzed quantitatively by an Agilent $6890 \mathrm{~N}$ gas chromatograph with a sulfur chemiluminescence detector (GC-SCD) for quantitative analysis.

\section{Results and discussion}

\section{Identification of alkylates between thiophene and 2,5-dimethyl-1,5-hexadiene}

By reason of very low content of sulfur compounds in the gasoline, the product after reaction was concentrated to improve the detectable rate of sulfur compounds, and the accuracy of qualitative analysis before the samples was tested by GC/MS. Therefore, the chromatogram was not a complete molecular distribution spectrogram for the product. Here, only the compounds containing sulfur atom are discussed to detect sulfur transformation reaction of thiophene. Chromatogram and mass spectrum of GC-MS for alkylates between thiophene are depicted in Figs. 1, 2, and 3. The peaks between 5 and 15 min in Fig. 1 are hydrocarbon compounds of the model oil. And the a peak (residence time $27.15 \mathrm{~min}$ ) and $\mathrm{b}$ peak (residence time $34.77 \mathrm{~min}$ ) in Fig. 1 are the alkylates of thiophene and 2,5dimethyl-1,5-hexadiene, which had been proved by the mass spectrum. The $\mathrm{a}$ and $\mathrm{b}$ peaks of Fig. 1 correspond to the mass spectrum of Figs. 2, and 3, respectively. The mass-to-charge ratio of the molecular ion peak of the mass

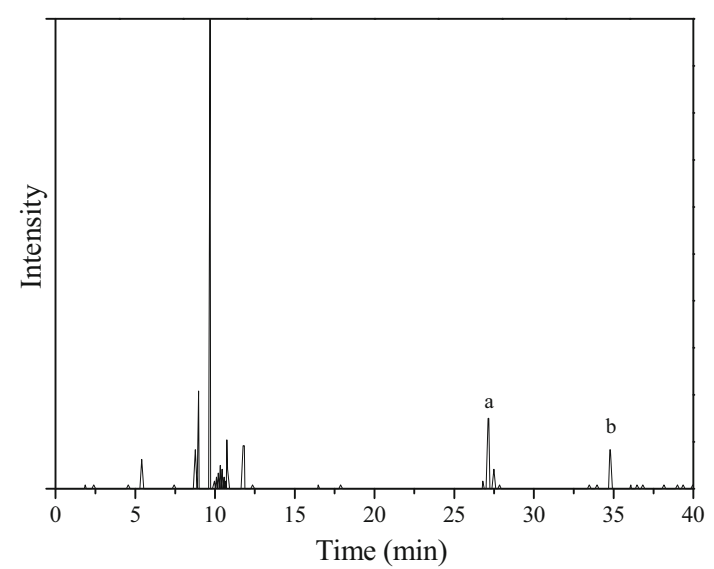

Fig. 1 Chromatogram of GC-MS for products of diolefin with thiophene 


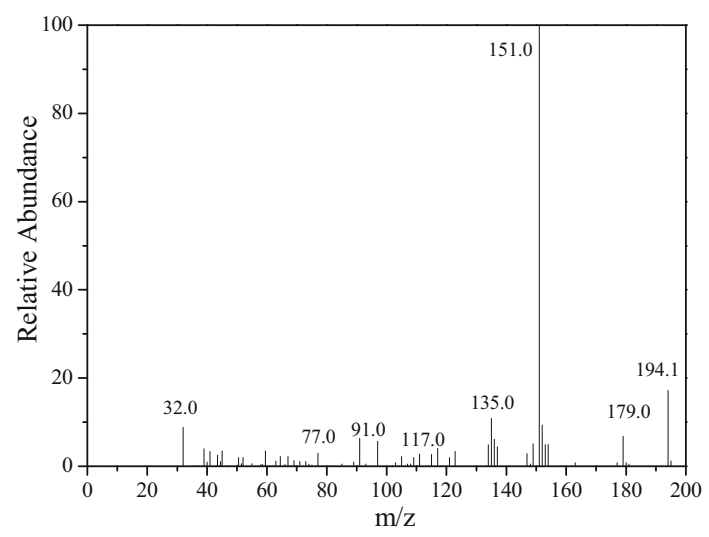

Fig. 2 Mass spectrum of GC-MS for mono-alkyl product of thiophene

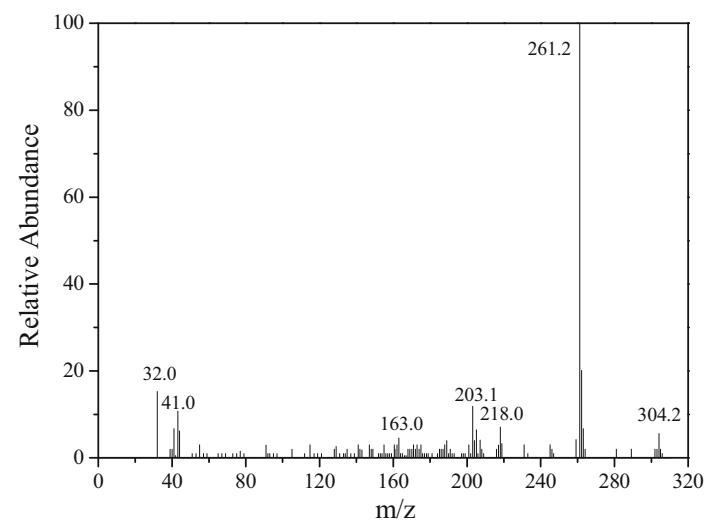

Fig. 3 Mass spectrum of GC-MS for di-alkyl product of thiophene

spectrum in Fig. 2 was 194.1, which could be considered as the mono-alkyl product (molecular weight 194.34) of thiophene (molecular weight 84.14) and 2,5-dimethyl-1,5hexadiene (molecular weight 110.20). Therefore, the a peak in the Fig. 1 was the mono-alkyl product of thiophene and 2,5-dimethyl-1,5-hexadiene. Similarly, the b peaks could be also inferred as mono-alkyl product of thiophene and 2,5-dimethyl-1,5-hexadiene by the mass spectrum. Based on the product analysis, the alkylation of thiophene and 2,5-dimethyl-1,5-hexadiene could form two kind of mono- and di-alkyl products over the benzenesulfonic acid catalyst.

\section{Alkylation performance of different kind of thiophenic sulfur}

Alkylation performance of different kinds of thiophenic sulfur compounds are displayed in Table 1. The results showed that the reaction performance had a great difference for the different structure thiophenic sulfur compounds. The order of the alkylation performance of the thiophenic sulfur compounds with 2,5-dimethyl-1,5-hexadiene was obtained as follows: 3-methyl-thiophene $\approx 2$ methyl-thiophene $>$ Thiophene $>2,5$-dimethyl-thiophene >2-methyl-5-ethyl-thiophene. Methyl-thiophene had the highest conversion. Methyl group was a electron-donating group, which could increase the density of electron cloud of thiophenic ring and improve the activity of electrophilic substitution of thiophenic ring. Therefore, the conversion of methyl-thiophene was higher than that of thiophene. However, as the branched chain increased, like 2,5-dimethyl-thiophene, the steric hindrance was improved and decreased the activity of alkylation with 2,5-dimethyl-1,5hexadiene. Therefore, electron donating effect and steric hindrance of thiophenic sulfur compounds played important roles of alkylation performance, and the effect of steric hindrance was greater than that of electron donating effect.

\section{Effects of 1-hexene on thiophene alkylation with 2,5-dimethyl-1,5-hexadiene}

$5,10,15,20 \mathrm{wt} \%$ of 1-hexene was supplied into the model oil to investigate effects of 1-hexene on thiophene alkylation with 2,5-dimethyl-1,5-hexadiene, respectively. The results are displayed in Fig. 4.

From Fig. 4, it could be found that as the amount of olefin arose the conversion of thiophene could be facilitated. However, the increment of conversion was limited. It showed that mono-olefins also reacted with thiophene [9, 12], which led to an improvement of conversion of thiophene. Due to the higher reaction activity of diene than mono-olefins [8], the conversion of thiophene only had a slight increase when the olefin was introduced to the system.

\section{Effects of reaction conditions}

The catalytic activity of benzenesulfonic acid catalyst on the alkylation was tested by the blended model oil composed of $99.5 \mathrm{wt} \%$ of octane, $0.5 \mathrm{wt} \%$ of 2,5-dimethyl-1,5hexadiene and $200 \mu \mathrm{g} / \mathrm{g}$ thiophene. The reaction performance could be influenced by temperature, time and catalyst/feed weight ratio, and the optimum operating condition was confirmed by a series of experiments as shown below.

\section{Effect of temperature}

Under the role of acidic catalyst, the diene not only take an alkylation with thiophene, but also could take intermolecular and inner-molecular polymerization reaction. The effect of reaction temperature on the conversion of thiophene and the conversion of diene in the alkylation 
Table 1 Alkylation performance of different kinds of thiophenic sulfur compounds

\begin{tabular}{llll}
\hline $\begin{array}{l}\text { Thiophenic sulfur } \\
\text { compounds }\end{array}$ & $\begin{array}{l}\text { Sulfur content } \\
\text { in feed } \\
(\mu \mathrm{g} / \mathrm{g})\end{array}$ & $\begin{array}{l}\text { Sulfur content } \\
\text { in product } \\
(\mu \mathrm{g} / \mathrm{g})\end{array}$ & $\begin{array}{l}\text { Conversion } \\
(\%)\end{array}$ \\
\hline Thiophene & 311 & 83 & 73.2 \\
2-Methyl-thiophene & 304 & 53 & 82.7 \\
$\begin{array}{l}\text { 3-Methyl-thiophene } \\
\text { 2,5-Dimethyl- }\end{array}$ & 323 & 52 & 83.9 \\
$\begin{array}{l}\text { thiophene } \\
\text { 2-Methyl-5-ethyl } \\
\text {-thiophene }\end{array}$ & 298 & 135 & 57.4 \\
\end{tabular}

Reaction conditions: stirring rate $500 \mathrm{rpm}$, temperature $85^{\circ} \mathrm{C}$, catalyst/feed weight ratio $10 \%$, time $80 \mathrm{~min}$

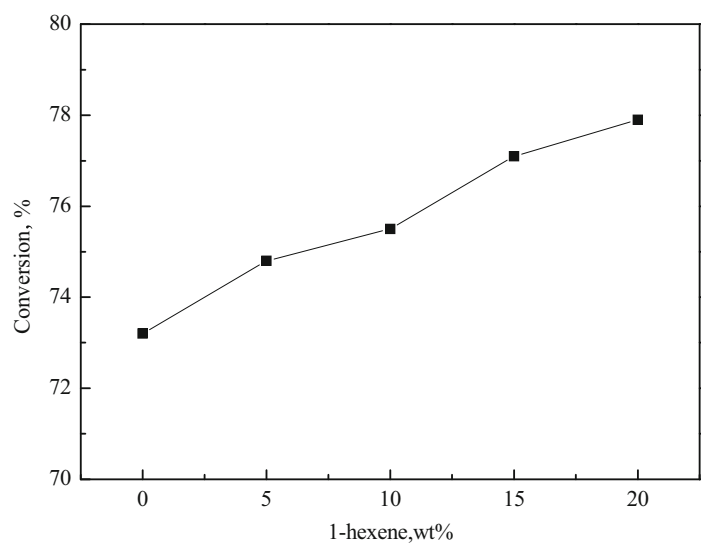

Fig. 4 Effects of different amounts of hexene on thiophene alkylation. Reaction conditions: stirring rate $500 \mathrm{rpm}$, temperature $85{ }^{\circ} \mathrm{C}$, catalyst/feed weight ratio $10 \%$, time $80 \mathrm{~min}$

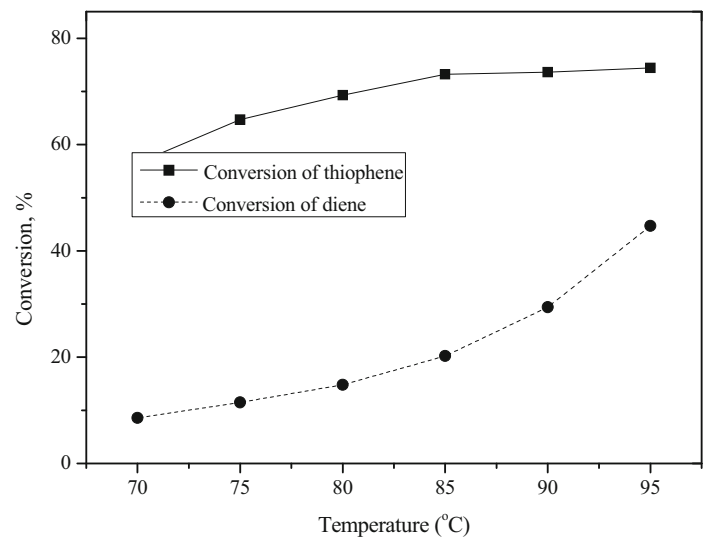

Fig. 5 Effect of temperature on conversion of thiophene. Other conditions: stirring rate $500 \mathrm{rpm}$, catalyst/feed weight ratio $10 \%$, time $80 \mathrm{~min}$

process was shown in Fig. 5. At first, the conversion of thiophene was increased rapidly with an increasing temperature. And then, when the temperature increased beyond
$85{ }^{\circ} \mathrm{C}$, the conversion of thiophene gradually leveled off to reach a stable value of around $73 \%$. However, when the temperature continued to rise, the polymerization of the diene would be accelerated. Especially the temperature rise from 90 to $95{ }^{\circ} \mathrm{C}$, the conversion of diene was improved from 29 to $44 \%$. Because the polymerization of the diene is an endothermic reaction [15] and the reaction rate of the polymerization can be improved by an increase of reaction temperature. By comparison with results of $\mathrm{Ke}$ et al., the conversion of diene was from 62 to $96 \%$ over a series of compound systems of $\operatorname{Br} \varphi n s t e d$ acidic ionic liquid with sulfuric acid under $30{ }^{\circ} \mathrm{C}$ and the conversion of diene was only $20 \%$ over benzenesulfonic acid under $85{ }^{\circ} \mathrm{C}$. These showed that benzenesulfonic acid exhibited relatively weak ability for the polymerization of diene in the alkylation process. From the above, the optimum reaction temperature was chosen as $85^{\circ} \mathrm{C}$.

\section{Effect of time}

The effect of time on the conversion of thiophene was tested at $85{ }^{\circ} \mathrm{C}$ and catalyst/feed weight ratio of $10 \%$. The results are depicted in Fig. 6. Figure 6 shows that the conversion only reached $47 \%$ when the system was heated and stirred for $50 \mathrm{~min}$. As the time increased, the conversion was continuously improved. When the temperature was extended to $80 \mathrm{~min}$, the conversion reached up to $73 \%$ and started to increase slowly. The conversion could not be effectively improved by an increase of reaction time. Therefore, the optimized reaction time could be confirmed as $80 \mathrm{~min}$.

\section{Effect of catalyst/feed weight ratio}

Effect of catalyst/feed weight ratio was also investigated at the temperature of $85{ }^{\circ} \mathrm{C}$ and reaction time $80 \mathrm{~min}$. The

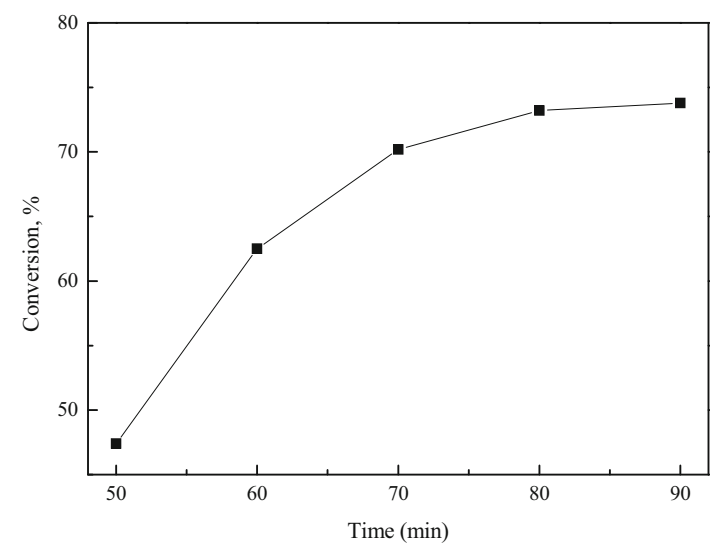

Fig. 6 Effect of time on conversion of thiophene. Other conditions: stirring rate $500 \mathrm{rpm}$, temperature $85{ }^{\circ} \mathrm{C}$, catalyst/feed weight ratio $10 \%$ 


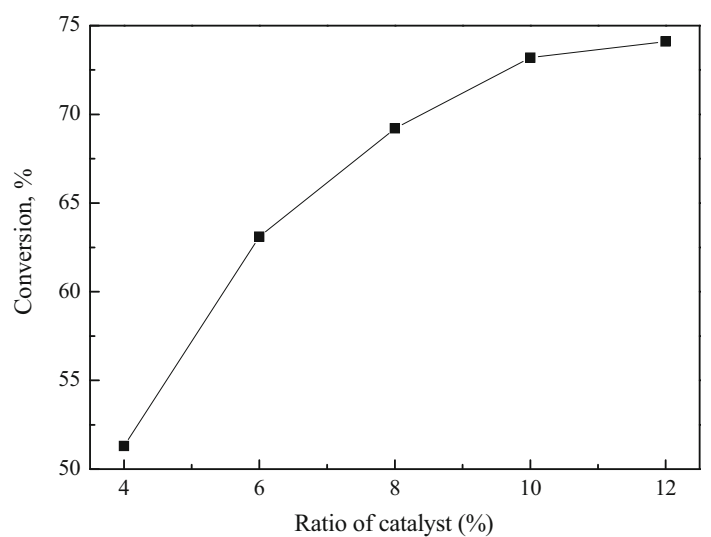

Fig. 7 Effect of catalyst/feed weight ratio on conversion of thiophene. Other conditions: stirring rate $500 \mathrm{rpm}$, temperature $85^{\circ} \mathrm{C}$, time $80 \mathrm{~min}$

results are displayed in Fig. 7. The line graph clearly showed that the conversion of thiophene in the alkylation with 2,5-dimethyl-1,5-hexadiene was improved by increasing the catalyst/feed weight ratio. When the amount of benzenesulfonic acid was increased from 4 to $10 \%$, the conversion of thiophene could be rapidly improved from 55 to $73 \%$. If the amount of benzenesulfonic acid continued to rise, the increase of the conversion started to be slow. Therefore, on account of the operating cost, the better catalyst/feed weight ratio was confirmed to be $10 \%$.

\section{Recycle of benzenesulfonic acid catalyst}

To investigate the reusable property of the catalyst at the optimized operating conditions above, the catalyst was reused for eight times and the results are shown in Fig. 8 . The results indicated that benzenesulfonic acid had good

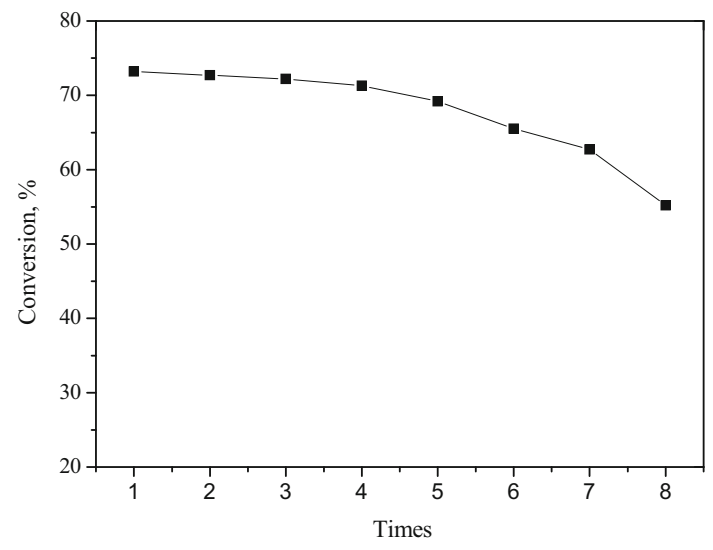

Fig. 8 Catalytic stability of benzenesulfonic acid on the alkylation of thiophene with 2,5-dimethyl-1,5-hexadiene. Reaction conditions: stirring rate $500 \mathrm{rpm}$, temperature $85{ }^{\circ} \mathrm{C}$, catalyst/feed weight ratio $10 \%$, time $80 \mathrm{~min}$ catalytic stability on the alkylation of thiophene with 2,5dimethyl-1,5-hexadiene. Although the conversion of thiophene had a decrease by $2 \%$ after the catalyst was used for four times, the catalyst still exhibited some recycle-use performance. From the fifth time of reuse, the conversion of thiophene started to go down quickly, which might be caused by the dissolution of benzenesulfonic acid in the model oil, polymerization of benzenesulfonic acid with olefins or other loss. Hence, the fresh catalyst should be added into the reaction system periodically and quantitatively to maintain the catalytic activity.

\section{Conclusions}

Benzenesulfonic acid as a catalyst for the thiophene alkylation with 2,5-dimethyl-1,5-hexadiene was studied and its reaction condition was optimized. As expected, benzenesulfonic acid demonstrated good catalytic performance. The mono- and di-alkyl-thiophene was confirmed by GCMS. The order of the alkylation performance of the thiophenic sulfur compounds with 2,5-dimethyl-1,5-hexadiene was obtained over benzenesulfonic acid was as follows: 3-methyl-thiophene $\approx 2$-methyl-thiophene >Thiophene $>2$, 5-dimethyl-thiophene $>2$-methyl-5-ethyl-thiophene. The optimal reaction condition was that temperature was $85{ }^{\circ} \mathrm{C}$, catalyst/feed weight ratio was $10 \%$ and time is $80 \mathrm{~min}$. Under the optimized condition, the conversion was nearly $73 \%$. The catalyst had some recycle-use performance. The catalytic activity could be maintained by addition of the fresh catalyst periodically and quantitatively.

Acknowledgments Financial support by the Scientific Research Starting Foundation for Doctors of Xi' an Shiyou University (Granted No. 2014BS19) is gratefully acknowledged.

Open Access This article is distributed under the terms of the Creative Commons Attribution 4.0 International License (http://creativecommons.org/licenses/by/4.0/), which permits unrestricted use, distribution, and reproduction in any medium, provided you give appropriate credit to the original author(s) and the source, provide a link to the Creative Commons license, and indicate if changes were made.

\section{References}

1. Breysse M, Djega-Mariadassou G, Pessayre S, Geantet C, Vrinat M, Pérot G, Lemaire M (2003) Deep desulfurization: reactions, catalysts and technological challenges. Catal Today 84:129

2. Debuisschert Q, Nocca JL (2003) PrimeG ${ }^{+\mathrm{TM}}$ commercial performance of FCC naphtha desulphurization technology. NPRA Annual Meeting, AM-03-26

3. Rock K, Shorey S (2003) Producing low sulphur gasoline reliably. NPRA Annual Meeting, AM-03-122 
4. Shih SS, Owens PJ, Palit S, Tryjankowski DA (1999) Mobil's OCT-gain process: FCC gasoline desulfurization reaches a new performance level. NPRA Annual Meeting, AM-99-30

5. Germana G, Abbott D, Turuga U (2004) Continued innovation. Hydrocarb Eng 9:35

6. Alexander BD, Huff GA, Vive R, Reagan WJ, Cayton RH (2000) Multiple stage sulfur removal process. US Patent 6059962

7. Xu C, Yang K, Liu Z, Qin Z, He W, Dai Q, Zhang J, Zhang F (2014) Superparamagnetic supported catalyst $\mathrm{H}_{3} \mathrm{PW}_{12} \mathrm{O}_{40} / \gamma-\mathrm{Fe}_{2} \mathrm{O}_{3}$ for alkylation of thiophene with olefine. Chin J Chem Eng 22:305

8. Ke M, Tang Y, Cao W, Peng H, Zhou A (2008) Study on alkylation reaction of diolefin with thiophene. J Xi' an Shiyou UnivSC 23:75

9. Zhang Z, Niu X, Liu S, Zhu X, Yu H, Xu L (2008) The performance of HMCM-22 zeolite catalyst on the olefin alkylation thiophenic sulfur in gasoline. Catal Commun 9:60

10. Hu L, Zhang Z, Xie S, Liu S, Xu L (2009) Effect of grain size of zeolite $\mathrm{Y}$ on its catalytic performance in olefin alkylation thiophenic sulfur process. Catal Commun 10:900
11. Wang R, Wan J, Li Y, Sun H (2014) An improvement of MCM41 supported phosphoric acid catalyst for alkylation desulfurization of fluid catalytic cracking gasoline. Fuel 143:504

12. Arias M, Laurenti D, Geantet C, Vrinat M, Hideyuki I, Yoshimura Y (2008) Gasoline desulfurization by catalytic alkylation over silica-supported heteropolyacids: from model reaction to real feed conversion. Catal Today 130:190

13. Tang X, Yuan J, Li J, Zhang Y, Hu T (2015) Alkylation desulfurization of FCC gasoline catalyzed by pyridine ionic liquid. J Fuel Chem Technol 43:442

14. Ke M, Zhou A, Cao W, Song Z, Jiang Q (2008) The application of brensted acidic ionic liquids in alkylation desulfurization of gasoline. J PetroChem Univ 21:25

15. Belliere V, Geantet C, Vrinat M, Ben-Taarit Y, Yoshimura Y (2004) Alkylation of 3-methylthiophene with 2-methyl-2-butene over a zeolitic catalyst. Energy Fuels 18:1806 